Sel ecti ve recovery of i ndi umfrom the et ching waste sol ut i on of the $\mathrm{fl}$ at-panel di spl ay fabri cat $i$ on process

\begin{tabular}{|l|l|}
\hline 著者 & $\begin{array}{l}\text { Hasegawa H r oshi, Rahman I smai I M M, Umehar a } \\
\text { Yoshi hi ro, Sawai Hi kar u, Naki Ter uya, Fur usho } \\
\text { Yoshi aki, M zut ani Sat oshi }\end{array}$ \\
\hline $\begin{array}{l}\text { j our nal or } \\
\text { publ i cat i on ti tl e }\end{array}$ & M cr ochemi cal J our nal \\
\hline vol une & 110 \\
\hline page r ange & $133-139$ \\
\hline year & $2013-09-01$ \\
\hline URL & ht t p: //hdl . handl e. net /2297/34666 \\
\hline
\end{tabular}


The research article is originally published at Microchemical Journal

An Elsevier Journal

http://www.journals.elsevier.com/microchemical-journal/

The original publication is available at: http://dx.doi.org/10.1016/j.microc.2013.03.005

\section{Selective Recovery of Indium from the Etching Waste Solution of the Flat-Panel Display Fabrication Process}

Hiroshi Hasegawa, ${ }^{1, *}$ Ismail M. M. Rahman, ${ }^{2,3, *}$ Yoshihiro Umehara, ${ }^{2}$ Hikaru Sawai, ${ }^{2}$ Teruya Maki, ${ }^{1}$ Yoshiaki Furusho, ${ }^{4}$ Satoshi Mizutani ${ }^{5}$

${ }^{1}$ Institute of Science and Engineering, Kanazawa University, Kakuma, Kanazawa 920-1192, Japan

${ }^{2}$ Graduate School of Natural Science and Technology, Kanazawa University, Kakuma, Kanazawa 920-1192, Japan

${ }^{3}$ Department of Applied and Environmental Chemistry, University of Chittagong, Chittagong 4331, Bangladesh

${ }^{4}$ GL Sciences Inc., Nishishinjuku 6-22-1, Shinjuku, Tokyo 163-1130, Japan

${ }^{5}$ Graduate School of Engineering, Osaka City University, Sugimoto 3-3-138, Sumiyoshi-Ku, Osaka 5588585, Japan

*Author(s) for correspondence.

E-mail: hhiroshi@t.kanazawa-u.ac.jp (H. Hasegawa). I.M.M.Rahman@gmail.com (I.M.M. Rahman).

Tel/ Fax: +81-76-234-4792

Please Cite the article as: H. Hasegawa, I.M.M. Rahman, Y. Umehara, H. Sawai, T. Maki, Y. Furusho and S. Mizutani, Selective recovery of indium from the etching waste solution of the flat-panel display fabrication process, Microchemical Journal, 110: 133-139, 2013. 


\begin{abstract}
The waste byproducts from the indium-consuming fabrication processes are considered as the viable resource for indium due to the unique preference to the element in designing optoelectronic devices. The present work introduces a new technique for the selective recovery of indium from the etching waste, which produced during the patterning of indium tin oxide (ITO) layer on the flatpanel displays. The process includes the application of a solid phase extraction (SPE) assembly, known as molecular recognition technology (MRT) gel, consisting of a metal-selective ligand immobilized to silica gel or polymer substrates. The samples were the real solution of etching waste from the liquid-crystal display fabrication process, and the simulated waste solution prepared using the commercially available etching solution composition containing ethanedioic acid. The retention and the corresponding indium recovery rate (\%) were the key characteristics for the appraisal of MRT-SPE types: AnaLig TE 02 (TE 02), AnaLig TE 03, AnaLig TE 07, AnaLig TE 13 and AnaLig PM 02. The other conclusive factors were the influence of ion intensity in solution and the interfering effects from tin, the co-content element in the ITO-formulation. The TE 02 MRT-SPE came across all the requisite aspects for the selective recovery of indium from the etching effluent. The indium retention or recovery with TE 02 MRT-SPE from the real etching waste solution was in the range of 97 to $99 \%$ with the relative standard deviation of $<4.4 \%$. The separation of the ITO co-element tin from the waste mixture was successively selective, and thereby minimizes the possibility of interference. A three-step elution with $0.3 \mathrm{~mol} \mathrm{~L}^{-1} \mathrm{HNO}_{3}, 6 \mathrm{~mol} \mathrm{~L}{ }^{-1} \mathrm{HCl}$ and $1 \mathrm{~mol}$ $\mathrm{L}^{-1} \mathrm{HCl} / 10$ mmol L ${ }^{-1}$ EDTA was required to accomplish the sequential selectivity in the process. The indium retention capacity of the TE 02 MRT-SPE was $0.147 \mathrm{mmol} \mathrm{g}^{-1}$.
\end{abstract}

\title{
Keywords
}

Separation; Indium; Tin; Indium tin oxide; Etching wastewater; Solid phase extraction 


\subsection{Introduction}

Transparent conducting oxides (TCOs) are extensively used in flat-panel displays (FPDs) (e.g. liquid-crystal display, plasma display panel), solar panels, organic light-emitting diodes, or in other electro-optical devices as transparent electrodes [1-4]. TCOs of binary, ternary or quaternary compositions combining In, Zn, Cd, Sn and Ga have been reported [5-9], while the Sn-doped $\mathrm{In}_{2} \mathrm{O}_{3}$ (ITO), F-doped $\mathrm{SnO}_{2}$, and Al-doped $\mathrm{ZnO}$ are acclaimed for the properties required for transparent electrodes [9]. ITO thin film is the most used among the TCOs, and industrially recognized in terms of the better characteristics of transparency to visible light, electric conduction and thermal reflection $[4,10]$. The major component of ITO is metal indium, which is well thought-out as 'rare' due to its increasing demand and limiting supply resources [11]. The recent researches, hence, increasingly focus on the waste materials from the indium-consuming manufacturing processes as the useful secondary resource for indium, other than the refinery production. The prospective waste resources that are studied for the recovery of indium are ITO-scrap [12-15], end-of-life liquid crystal displays $[13,16,17]$ and etching waste $[18,19]$.

ITO thin film is usually applied on the FPDs using DC magnetron sputtering process, in which less than one-third of the ITO target are transported to the glass panel leaving a significant fraction as either ITO scrap or residue [12, 19]. The patterning of the resultant ITO layer on the FPDs is generally conducted through a photolithography process using the etching in acidic solutions [4]. The waste solution thus produced from the etching process contains the residual ITO fraction, and can be used as a secondary resource for the recovery of indium [18, 19].

Recovery of soluble indium from the mixed matrix solution using solvent extraction [20], chemical precipitation [21, 22], ion-exchange resin [23-25], and liquid membrane [26] has been reported. However, these conventional approaches are disadvantageous when the concentration of indium is low in solution owing to the lower feed/recovery ratio, bulk consumption of reagent, high-energy requirements, generation of toxic sludge or effluent, and so forth [27]. The effect of coexisting ions in the aqueous mixtures has also hardly ever been considered in the reagent-based separation processes [18]. 
The etching waste solution from the fabrication process of FPDs contains about $2 \%$ of indium [18]. The techniques by far attempted for the recovery of indium from the etching waste were solvent extraction combined with electrolytic refining [18] and supercritical carbon dioxide extraction [19]. However, due to the ability to attain high concentration factor, solid phase extraction (SPE) technique is preferentially recommended for the separation of metal ions from aqueous solutions as compared to the other separation techniques when the target ion content is low in the feed solution $[28,29]$. Although SPE offers fast separation of an analyte of interest from the solution, the main difficulty in using SPE scheme for the recovery of indium from the etching wastewater is the comparative selectivity of the SPE material toward the content-species in the solution [30-33]. ITO is formulated by doping $\mathrm{In}_{2} \mathrm{O}_{3}$ with approximately $10 \%$ of $\mathrm{SnO}_{2}$, and tin appears as the major impurity in the recovery process of indium from the ITO-waste [12]. The separation process becomes further challenging due to the chemical similarity between indium and tin $[34,35]$. Hence, SPE-type with sufficiently high and selective affinity toward trace levels of indium is required to treat ITO-waste solutions.

In this work, an SPE-type known as molecular recognition technology (MRT) gel is used that claimed to possess selectivity in binding the analyte of interest even in highly concentrated matrix solutions [36]. The comparative selectivity behavior of the MRT-SPE variants (AnaLig TE 02, AnaLig TE 03, AnaLig TE 07, AnaLig TE 13 and AnaLig PM 02) toward indium or tin and the corresponding rate of recovery via elution were evaluated along with other key factors for separation. The observations are used to design a process for the recovery of indium from the mixed matrix etching waste solution. Besides the application of SPE, the distinctive point of the proposed technique is the non-destructive and rapid recovery of the indium from the liquid ITOwaste mixture through the concurrent confinement of the interfering tin species.

\subsection{Experimental}

\subsection{Instrumentation}

An inductively coupled plasma optical emission spectrometer (ICP-OES) of the iCAP 6300 model from Thermo Fisher Scientific (Waltham, MA) was used for the metal analysis. The ICPOES was operated using the $1.15 \mathrm{~kW}$ RF power at the torch. Argon was used as the flow gas 
passing at the rate of $12 \mathrm{~L} \mathrm{~min}^{-1}$ in the plasma, $1 \mathrm{~L} \mathrm{~min}^{-1}$ in the auxiliary, and $0.5 \mathrm{~L} \mathrm{~min}{ }^{-1}$ in the nebulizer. The integration time was $30 \mathrm{~s}$. Each measurement was performed at three replicates.

A GL-SPE vacuum manifold kit from GL Sciences (Tokyo, Japan) in combination with an CAS-1 air pump from AS ONE (Osaka, Japan) was used to perform the SPE. The Aqua Loader III from GL Sciences (Tokyo, Japan) was used as the SPE flow-rate regulator. A Navi F-52 pH meter from Horiba Instruments (Kyoto, Japan) fitted out with a combination electrode was used for $\mathrm{pH}$ measurements. An Arium Pro water purification system from Sartorius Stedim Biotech GmbH (Göttingen, Germany) was used to prepare the ultrapure water of resistivity $>18.2 \mathrm{M} \Omega \cdot \mathrm{cm}$.

\subsection{Materials}

\subsubsection{Etching waste solution}

The real etching waste solution was collected from a Japanese manufacturer producing liquidcrystal display panels via Kanto Chemical (Tokyo, Japan). The manufacturer has been introduced as 'anonymous' as per request from the supplier to avoid the violation of proprietary rights. The ICP-OES analysis of the real etching effluent revealed the following contents: In, $386.3 \mathrm{mg} \mathrm{L}^{-1}$; Sn, $38.75 \mathrm{mg} \mathrm{L}^{-1}$; Sr, $0.043 \mathrm{mg} \mathrm{L}^{-1}$; and Ti, $0.755 \mathrm{mg} \mathrm{L}^{-1}$. The solution $\mathrm{pH}$ was 1.5.

The simulated solution of etching waste was prepared by adding $300 \mathrm{mg} \mathrm{L}^{-1}$ indium and $30 \mathrm{mg}$ $\mathrm{L}^{-1}$ tin in ITO-06N etching solution composition containing $5 \%$ ethanedioic acid in water available commercially from Kanto Chemical (Tokyo, Japan) following the procedure as described elsewhere [37]. The $\mathrm{pH}$ of the simulated solution was maintained within the range of 1 to 1.5.

\subsubsection{SPE materials}

SPE-types, including MRT gel, chelating resin, and ion-exchange resin were used. The AnaLig TE 02 (TE 02), AnaLig TE 03 (TE 03), AnaLig TE 07 (TE 07), AnaLig TE 13 (TE 13) and AnaLig PM 02 (PM 02) were the MRT gel types from GL Sciences (Tokyo, Japan), which have a silica gel base containing crown ether functional groups. The Chelex-100 (C 100) (styrene divinylbenzene base containing iminodiacetic acid functional groups) from Bio-Rad Laboratories (Hercules, CA), NOBIAS Chelate PA-1 (PA 1) (hydrophilic methacrylate base containing polyaminopolycarboxylic acid functional groups) and NOBIAS Chelate PB-1 (PB 1) (divinylbenzene/ methacrylate polymer base containing polyamino-polycarboxylic acid functional groups) from 
Hitachi High-Technologies (Tokyo, Japan) were the chelating resin types. The NOBIAS Ion SA-1 (SA 1) (hydrophilic methacrylate base containing quaternized amine functional groups) and NOBIAS Ion SC-1 (SC 1) (hydrophilic methacrylate base containing sulfonic acid functional groups) from Hitachi High-Technologies (Tokyo, Japan) were the ion-exchange resin types.

\subsubsection{Chemicals and laboratory wares}

All the chemicals were of reagent grade, and used without further purification. Indium or tin standard solutions, $\mathrm{NaNO}_{3}$ salt, $\mathrm{HNO}_{3}$ and $\mathrm{HCl}$ were purchased from Kanto Chemical (Tokyo, Japan). The $\mathrm{HNO}_{3}$ was used for rinsing of the SPE assembly, for adjusting the solution $\mathrm{pH}$ of the simulated etching waste or for elution. The $\mathrm{HCl}$ is used for the elution and for the cleaning of laboratory wares. The ITO-06N etching solution composition is fortified with $\mathrm{NaNO}_{3}$ to obtain a mix of the $0.1 \mathrm{~mol} \mathrm{~L}^{-1}$ concentration, and used for the conditioning of the SPE-types. A PlasmaCAL multi-element solution in $5 \% \mathrm{HNO}_{3}$ containing twenty-one different metal species from SCP Science (Québec, Canada) was used to assess the effect of matrix ions. All working solutions were prepared from the stock solutions by dilution with ultrapure water.

The laboratory wares include low-density polyethylene bottles from Nalge Nunc (Rochester, NY), perfluoroalkoxy tubes and micropipette tips from Nichiryo (Tokyo, Japan). The accessories have been cleaned before and after each use by overnight soaking in Scat 20X-PF alkaline detergent from Nacalai Tesque (Kyoto, Japan) and then in $4 \mathrm{~mol} \mathrm{~L}{ }^{-1} \mathrm{HCl}$, and rinsing with ultrapure water after each of those steps.

\subsection{Methods}

SPE-assembly packed in $5 \mathrm{~mL}$ mini-columns was used. The process consisted of rinsing with 1 mol L ${ }^{-1} \mathrm{HNO}_{3}$ (2 to $3 \mathrm{~mL}$ ) and ultrapure water (5 mL); conditioning with $0.1 \mathrm{~mol} \mathrm{~L}^{-1} \mathrm{NaNO}_{3}$ in ITO-06N solution $(\sim 15 \mathrm{~mL})$; sample loading $(2+2 \mathrm{~mL})$; washing with ultrapure water $(2+2 \mathrm{~mL})$; and elution with $\mathrm{HNO}_{3}, \mathrm{HCl}$, EDTA or their mixtures in combination with ultrapure water depending either on the SPE-type or the target element (4 to $12 \mathrm{~mL}$ ). The gravity flow was adequate for separation, which maintained the flow-rate between 0.2 and $0.5 \mathrm{~mL} \mathrm{~min}^{-1}$.

The rinsing step was for the elimination of any foreign species that might remain within the SPE-columns. The conditioning step was used to attain the equilibrium chemical state within the 
SPE-assembly and to suppress any possible side-effect from the rinsing step. The sample loading, washing and elution steps were the principal steps of the separation process. The processed solution obtained at each of those steps has been labeled, respectively, as the column outflow, wash outflow and elution outflow and was measured for the metal concentrations in ICP-OES, including that of the sample. The element mole total in the elution outflow was compared with the cumulative number of the element moles present in all the outflows (i.e., column outflow, wash outflow and elution outflow), and the percentage rate of element retention in the SPE is attained. The aggregate of element mole total in all the outflows was compared with the element moles in the sample solution to compute the recovery rate in percentage. The reported values are averaged from at least three replicate tryouts.

\subsection{Results and discussion}

\subsection{Comparative evaluation of the SPE-types}

\subsubsection{Retention of indium and tin}

The primary objective of the selective SPE from the mixed matrix is the maximum retention of the target element in the solid-phase. A comparative scenario of indium or tin retention rate (\%) in different MRT-SPE types and other SPE types is shown in Fig. 1a and 1b, respectively. The indium retention rate (\%) was at least 97.1 in the MRT-SPE types, except that in the TE 07 (44.0 \pm 0.8 ), while the tin was retained quantitatively. The three candidates of the other SPE-types showed notable indium retention (\%) efficiency (C 100: $86.3 \pm 0.4$, PA 1: $87.4 \pm 0.2$, PB 1: $96.1 \pm 4.4$ ). However, the performance (\%) is inferior to that of the MRT-SPE options (TE 02: $99.9 \pm 0.9$, TE 03: $97.1 \pm$ 0.4, TE 13: $100 \pm 1.1$, PM 02: $99.9 \pm 0.8$ ). The other SPE-types were better competent in retaining tin, except for the SC 1 , then the indium.

Macrocyclic chelants, such as crown ethers, immobilized on the solid-phase are used to design the MRT-SPE types [38, 39]. The excellent structural diversity and the superior guest selectivity of the crown ethers, among the parent macrocycles, are particularly effective for binding hard metal ions [40]. The macrocyclic chemistry coupled with the molecular recognition acts better than the typical ion-exchange or metal-chelant complex formation chemistry of the traditional SPE options 
[39, 41], which possibly result in the condescending retention performance with the MRT-SPE types.

\subsubsection{Recovery of indium and tin}

An SPE process can be accepted as effective not only with the thoroughgoing retention of the target element, but also with the selective recovery of the retained species from the solid-phase via elution. A high enrichment factor from the SPE process is obvious if the eluent possesses the capacity to elute the species with a minimum volume without affecting its precise analysis [42]. The eluent is usually a single liquid or a mixture of multiple liquids, which are applied either in a single dose or in a series. The recovery of the indium or tin that retained within the MRT-SPE (Fig. 2a) or other-SPE types (Fig. 2b) was attempted primarily with a mixture of $\mathrm{HNO}_{3}\left(1 \mathrm{~mol} \mathrm{~L}{ }^{-1}, 2 \mathrm{~mL}\right.$ and $\left.6 \mathrm{~mol} \mathrm{~L}{ }^{-1}, 1 \mathrm{~mL}\right)$ and ultrapure water $(1 \mathrm{~mL})$. The aforementioned composition was used for the selective separation of toxic metal-species from the metal-affluent matrix with the other MRTSPE variants [17] and the other SPE-types [43]. The C 100, PA 1 or PB 1 SPE-types were able to retain $>86 \%$ of total indium or tin, and the recovery of the 'captured' content was non-selective (Fig. 2b). The retained total indium contents in the MRT-SPE types recovered selectively with the stated eluent composition, while the tin-content remained as is in the solid-phase (except that for TE $02,31.7 \pm 6.8$, and TE $03,22.8 \pm 4.7$ ). The selectivity in recovery attained with the MRT-SPE types might be due to the difference in the patterns of inclusion of the target metal species in the macrocyclic cavity [44], which were determined by the combination of size, configuration, electronic interaction, charge, wetting, and other factors of the target species [45].

The recovery of tin from the MRT-SPE with different eluents was attempted for the regeneration and reuse. Besides the composition of $\mathrm{HNO}_{3}\left(1\right.$ and $\left.6 \mathrm{~mol} \mathrm{~L}{ }^{-1}\right)$ and ultrapure water, 6 mol L ${ }^{-1} \mathrm{HCl}(4 \mathrm{~mL})$ and $1 \mathrm{~mol} \mathrm{~L}^{-1} \mathrm{HCl} / 10 \mathrm{mmol} \mathrm{L}^{-1}$ EDTA (4 mL) were the other two eluent options (Fig. 2c). The eluents were independently unable to back-extract tin from the MRT-SPE structure, which indicates comparatively stronger attachment of tin within the MRT-SPE structure than that of the indium. The incorporation of tin appeared much stronger in the TE 13 or PM 02 with a cumulative recovery rate (\%) of $1.5 \pm 0.1$ and $48.8 \pm 1.9$, respectively, with the series application of the eluents. The aggregate tin recovery (\%) from the TE 07 was favorable $(95.2 \pm$ 
1.8), while its practical application prospect is limited because of the below $45 \%$ indium retention. The series-elution process offered a rather substantial tin-recovery from the TE $02(91.2 \pm 5.4)$ and TE 03 (100 \pm 2.6$)$, although it included the fraction released simultaneously (TE 02: $31.7 \pm 6.8$, TE 03: $22.8 \pm 4.7)$ during the recovery process of indium using the eluent composition of $\mathrm{HNO}_{3}(1$ and $6 \mathrm{~mol} \mathrm{~L}^{-1}$ ) and ultrapure water. Such instantaneous recovery behavior of indium and tin might be interrelated to the higher $\mathrm{HNO}_{3}$ concentration in the eluent mixture. The fact was further confirmed from the comparative recovery behavior of indium and tin from the TE 02 and TE 03 with the 0.1 to $5 \mathrm{~mol} \mathrm{~L}^{-1} \mathrm{HNO}_{3}$ (Fig. 2d) and, accordingly, the indium-only recovery was confirmed with the $0.3 \mathrm{~mol} \mathrm{~L}^{-1} \mathrm{HNO}_{3}$.

\subsubsection{Effect of matrix-component intensity and diversity}

The intensity and diversity of the matrix components might interfere in the process of separation or compromise the selectivity behavior of the MRT-SPE [17, 32]. Therefore, the effect of the intensity and diversity of the co-existing contents in simulated etching waste solution on the indium or tin retention pattern was evaluated. The matrix ion intensity was varied using the $\mathrm{NaNO}_{3}$ concentration of 0.05 to $1.0 \mathrm{~mol} \mathrm{~L}^{-1}$, and $20 \mathrm{mg} \mathrm{L}^{-1}$ each of the 21-different elements (Al, Ba, Be, Bi, Ca, Cd, Co, Cu, Fe, Ga, In, Mg, Mn, Ni, Pb, Sc, Sr, Ti, V, Y, and Zn) was added to achieve the matrix-component diversity. A proportional decrease in the indium retention rate occurred with the increase in the matrix-component concentration, whereas the tin retention rates remain unchanged (Fig. 3a). The indium retention rate is also decreased, to some extent, with the presence of diverse elements in the matrix (Fig. 3b). The assessment narrowed to TE 02 and TE 03 MRT-SPE types owing to their considerable performance in the retention and selective recovery of indium and tin, and the TE 02 withstand better to the increased intensity or diversity of the matrix-components.

\subsection{Scheme for the selective recovery of indium}

The retention and recovery behavior of the different SPE-types to the indium or tin in solution enabled us to propose a scheme for the selective separation of the aforesaid elements from the etching effluents generated during the fabrication process of FPDs. The etching waste solution comprises the residual fraction of the sputtered ITO-target on the display panels, which typically contain a minute amount (less than $20 \mathrm{mg} \mathrm{L}^{-1}$ ) of different elements except the elements of indium, 
tin and oxygen as remain in the ITO-scrap [12]. Therefore, the key feature of the proposed scheme with the AnaLig TE 02 MRT-SPE is the quantitative retention of the indium or tin followed by the selective recovery of the elements as illustrated in detail in the Fig. 4.

\subsection{Application of the proposed scheme to the 'simulated' and 'real' etching waste solution}

\subsubsection{Selective recovery of indium}

The proposed scheme was applied for the selective recovery of indium from the simulated and real etching waste solution (Fig. 5). A sequential separation approach was required to accomplish the objective, which consists of the following steps: (a) simultaneous retention of the elements in the etching waste mixture, (b) recovery of the retained indium via elution with $0.3 \mathrm{~mol} \mathrm{~L}^{-1} \mathrm{HNO}_{3}$, and (c) back-extraction of the tin from the SPE-phase using $6 \mathrm{~mol} \mathrm{~L}^{-1} \mathrm{HCl}$ and $1 \mathrm{~mol} \mathrm{~L}^{-1} \mathrm{HCl} / 10$ mmol L ${ }^{-1}$ EDTA. The rate of indium retention or recovery from the simulated or real etching effluents was in the range of 97 to $99 \%$ and the relative standard deviation was below $4.4 \%$.

\subsubsection{Sample source, retention rate and sample loading flow-rate}

The gravity-flow was maintained throughout the process for sample loading and elution. Such flow-rate was adequate for the quantitative separation of indium or tin as confirmed from the subsequent ICP-OES analysis. An additional comparative observation was yet recorded between the sample loading flow-rate and the retention rate of indium or tin in the TE 02 MRT-SPE with the change in etching waste sample-types, e.g. simulated and real (Fig. 6). The retention rate of indium or tin from the simulated etching waste solution had a somewhat uniform trend ( $\geq 94 \%)$ even at a

very high flow-rate $\left(60 \mathrm{~mL} \mathrm{~min}^{-1}\right)$. However, the pattern observed with the real etching waste solution is completely different showing a maximum retention of indium or tin ( $\geq 99 \%)$ at the flowrate of $0.5 \mathrm{~mL} \mathrm{~min}{ }^{-1}$ and a gradual decrease with increasing flow-rates. The real etching effluent contains the ITO-residue, the solid solution of indium(III) oxide $\left(\operatorname{In}_{2} \mathrm{O}_{3}\right)$ doped with tin(IV) oxide $\left(\mathrm{SnO}_{2}\right)$ of 10:1 ratio. The $\mathrm{In}_{2} \mathrm{O}_{3}$ exhibits a cubic bixbyite structure, and the coordination does not seem to be modified by the presence of tin, while a more highly distorted oxygen environment around indium is predicted due to the insertion of tin [46]. Although the simulated solution composed of the same ratio of indium and tin used in ITO formulation, the chemical nature was 
obviously different from that of the actual process solution. Hence, the concurrent retention pattern observed for the real solution lacks for the simulated solution.

\subsubsection{Retention capacity}

The term 'retention capacity' is usually used to describe the stability of an SPE-type throughout the separation process, which can be computed from the breakthrough volume of the SPE-type, and total retained amount of an element $\left(\mathrm{mmol} \mathrm{g}^{-1}\right)$ in the solid phase [47]. The real etching waste solution was treated following the proposed separation scheme; the indium or tin is eluted and analyzed via ICP-OES. The indium retention capacity of the TE 02 MRT-SPE was $0.147 \mathrm{mmol} \mathrm{g}^{-1}$ (Fig. 7).

\subsection{Conclusion}

A process for the selective recovery of indium from the etching effluent generated during the ITO-layer patterning on the FPDs is proposed. The study includes the evaluation of several commercial SPE-types (TE 02, TE 03, TE 07, TE 13, PM 02, C 100, PA 1, PB 1, SC 1, SA 1) for the selective separation of indium from the matrix elements. The objectives are the maximum indium transfer from solution to the solid-phase and limit the intrusive elution of the ITO coelement tin. The MRT-SPE types, TE 02 and TE 03, could come across both the required points, while TE 02 performed better with the other additional factors such as, matrix-component diversity or intensity. The $\mathrm{HNO}_{3}$ solution $\left(0.3 \mathrm{~mol} \mathrm{~L}{ }^{-1}\right)$ was used for the selective recovery of the retained indium, and the recovery rate (\%) from the real etching waste solution was $99.8 \pm 2.2$.

\section{Acknowledgment}

This research was partially supported by the Grants-in-Aid for Scientific Research (24310056 and 24-02029) from the Japan Society for the Promotion of Science. 


\section{References}

[1] A. Shah, P. Torres, R. Tscharner, N. Wyrsch, H. Keppner, Photovoltaic technology: The case for thin-film solar cells, Science 285 (1999) 692-698.

[2] H.-K. Kim, K.-S. Lee, J.H. Kwon, Transparent indium zinc oxide top cathode prepared by plasma damage-free sputtering for top-emitting organic light-emitting diodes, Appl. Phys. Lett. 88 (2006) 012103.

[3] Y.-H. Tak, K.-B. Kim, H.-G. Park, K.-H. Lee, J.-R. Lee, Criteria for ITO (indium-tinoxide) thin film as the bottom electrode of an organic light emitting diode, Thin Solid Films 411 (2002) 12-16.

[4] Z.H. Li, E.S. Cho, S.J. Kwon, A new laser direct etching method of indium tin oxide electrode for application to alternative current plasma display panel, Appl. Surf. Sci. 255 (2009) 9843-9846.

[5] I. Hamberg, C.G. Granqvist, Evaporated Sn-doped $\mathrm{In}_{2} \mathrm{O}_{3}$ films: Basic optical properties and applications to energy-efficient windows, J. Appl. Phys. 60 (1986) R123-R160.

[6] Y.W. Heo, S.J. Park, K. Ip, S.J. Pearton, D.P. Norton, Transport properties of phosphorusdoped ZnO thin films, Appl. Phys. Lett. 83 (2003) 1128-1130.

[7] D.D. Edwards, T.O. Mason, F. Goutenoire, K.R. Poeppelmeier, A new transparent conducting oxide in the $\mathrm{Ga}_{2} \mathrm{O}_{3}-\mathrm{In}_{2} \mathrm{O}_{3}-\mathrm{SnO}_{2}$ system, Appl. Phys. Lett. 70 (1997) 1706-1708.

[8] T. Minami, T. Miyata, T. Yamamoto, Work function of transparent conducting multicomponent oxide thin films prepared by magnetron sputtering, Surf. Coat. Technol. 108-109 (1998) 583-587.

[9] W.T. Lim, L. Stafford, J.I. Song, J.S. Park, Y.W. Heo, J.H. Lee, J.J. Kim, S.J. Pearton, High-density plasma etching of indium-zinc oxide films in $\mathrm{Ar} / \mathrm{Cl}-2$ and $\mathrm{Ar} / \mathrm{CH} 4 / \mathrm{H}-2$ chemistries, Appl. Surf. Sci. 253 (2006) 2752-2757.

[10] D.S. Ginley, H. Hosono, D.C. Paine, Handbook of Transparent Conductors, Springer, New York, 2010.

[11] A.M. Alfantazi, R.R. Moskalyk, Processing of indium: A review, Miner. Eng. 16 (2003) 687-694.

[12] Y.H. Li, Z.H. Liu, Q.H. Li, Z.Y. Liu, L. Zeng, Recovery of indium from used indium-tin oxide (ITO) targets, Hydrometallurgy 105 (2011) 207-212.

[13] S. Virolainen, D. Ibana, E. Paatero, Recovery of indium from indium tin oxide by solvent extraction, Hydrometallurgy 107 (2011) 56-61.

[14] J.C. Park, The recovery of indium metal from ITO-scrap using hydrothermal reaction in alkaline solution, B. Korean Chem. Soc. 32 (2011) 3796-3798. 
[15] S.J. Hsieh, C.C. Chen, W.C. Say, Process for recovery of indium from ITO scraps and metallurgic microstructures, Mater. Sci. Eng. B-Adv. 158 (2009) 82-87.

[16] Y.S. Park, W. Sato, G. Grause, T. Kameda, T. Yoshioka, Recovery of indium from $\mathrm{In}_{2} \mathrm{O}_{3}$ and liquid crystal display powder via a chloride volatilization process using polyvinyl chloride, Thermochim. Acta 493 (2009) 105-108.

[17] H. Hasegawa, I.M.M. Rahman, Y. Egawa, H. Sawai, Z.A. Begum, T. Maki, S. Mizutani, Recovery of indium from end-of-life liquid-crystal display panels using aminopolycarboxylate chelants with the aid of mechanochemical treatment, Microchem. J. 106 (2013) 289-294.

[18] H.N. Kang, J.Y. Lee, J.Y. Kim, Recovery of indium from etching waste by solvent extraction and electrolytic refining, Hydrometallurgy 110 (2011) 120-127.

[19] H.M. Liu, C.C. Wu, Y.H. Lin, C.K. Chiang, Recovery of indium from etching wastewater using supercritical carbon dioxide extraction, J. Hazard. Mater. 172 (2009) 744-748.

[20] B. Gupta, A. Deep, P. Malik, Liquid-liquid extraction and recovery of indium using Cyanex 923, Anal. Chim. Acta 513 (2004) 463-471.

[21] M.A. Barakat, Recovery of lead, tin and indium from alloy wire scrap, Hydrometallurgy 49 (1998) 63-73.

[22] J. Jiang, D. Liang, Q. Zhong, Precipitation of indium using sodium tripolyphosphate, Hydrometallurgy 106 (2011) 165-169.

[23] A. Massoud, F. Abou El-Nour, H. Killa, U. Seddik, Chromatographic separation of In(III) from Cd(II) in aqueous solutions using commercial resin (Dowex 50W-X8), Cent. Eur. J. Chem. 8 (2010) 696-701.

[24] C. Xiong, X. Han, C. Yao, Sorption behavior of In(III) ions onto cation-exchange carboxylic resin in aqueous solutions: Batch and column studies, Separ. Sci. Technol. 45 (2010) 2368-2375.

[25] R.S. Marinho, C.N. da Silva, J.C. Afonso, J.W.S.D. da Cunha, Recovery of platinum, tin and indium from spent catalysts in chloride medium using strong basic anion exchange resins, J. Hazard. Mater. 192 (2011) 1155-1160.

[26] R. Guerriero, L. Meregalli, X. Zhang, Indium recovery from sulphuric solutions by supported liquid membranes, Hydrometallurgy 20 (1988) 109-120.

[27] T. Ogi, K. Tamaoki, N. Saitoh, A. Higashi, Y. Konishi, Recovery of indium from aqueous solutions by the Gram-negative bacterium Shewanella algae, Biochem. Eng. J. 63 (2012) 129-133. 
[28] C.F. Poole, Solid-phase extraction, in: D.W. Ian (Ed.) Encyclopedia of Separation Science, Academic Press, Oxford, 2000, pp. 1405-1416.

[29] V. Camel, Solid phase extraction of trace elements, Spectrochim. Acta B 58 (2003) 11771233.

[30] H. Hasegawa, I.M.M. Rahman, S. Kinoshita, T. Maki, Y. Furusho, Non-destructive separation of metal ions from wastewater containing excess aminopolycarboxylate chelant in solution with an ion-selective immobilized macrocyclic material, Chemosphere 79 (2010) 193-198.

[31] I.M.M. Rahman, Y. Furusho, Z.A. Begum, A. Sabarudin, S. Motomizu, T. Maki, H. Hasegawa, Selective separation of some ecotoxic transition metal ions from aqueous solutions using immobilized macrocyclic material containing solid phase extraction system, Cent. Eur. J. Chem. 9 (2011) 1019-1026.

[32] I.M.M. Rahman, Y. Furusho, Z.A. Begum, N. Izatt, R. Bruening, A. Sabarudin, H. Hasegawa, Separation of lead from high matrix electroless nickel plating waste solution using an ion-selective immobilized macrocycle system, Microchem. J. 98 (2011) 103-108.

[33] H. Hasegawa, I.M.M. Rahman, S. Kinoshita, T. Maki, Y. Furusho, Separation of dissolved iron from the aqueous system with excess ligand, Chemosphere 82 (2011) 1161-1167.

[34] J.-C. Park, The removal of tin from ITO-scrap via ozonization, B. Korean Chem. Soc. 30 (2009) 3141-3142

[35] J.-C. Park, The removal of tin from ITO-scrap using molten $\mathrm{NaOH}$, B. Korean Chem. Soc. 29 (2008) 255-256.

[36] R.M. Izatt, J.S. Bradshaw, R.L. Bruening, B.J. Tarbet, M.L. Bruening, Solid phase extraction of ions using molecular recognition technology, Pure Appl. Chem. 67 (1995) 1069-1074.

[37] H. Itoh, Resource Recovery Technology from Industrial Wastewater and Solid Wastes, CMC Publishing, Tokyo, 2010.

[38] J.S. Bradshaw, R.M. Izatt, Crown ethers: The search for selective ion ligating agents, Acc. Chem. Res. 30 (1997) 338-345.

[39] R.M. Izatt, J.S. Bradshaw, R.L. Bruening, M.L. Bruening, Solid phase extraction of ions of analytical interest using molecular recognition technology, Am. Lab. 26 (1994) 28C-28M.

[40] H. Tsukube, Double armed crown ethers and armed macrocycles as a new series of metalselective reagents: A review, Talanta 40 (1993) 1313-1324. 
[41] J.S. Bradshaw, R.M. Izatt, J.J. Christensen, K.E. Krakowiak, B.J. Tarbet, R.L. Bruening, S. Lifson, Stable silica gel-bound crown ethers. Selective separation of metal ions and a potential for separations of amine enantiomers, J. Incl. Phenom. Macro. 7 (1989) 127-136.

[42] D. Chen, C. Huang, M. He, B. Hu, Separation and preconcentration of inorganic arsenic species in natural water samples with 3-(2-aminoethylamino) propyltrimethoxysilane modified ordered mesoporous silica micro-column and their determination by inductively coupled plasma optical emission spectrometry, J. Hazard. Mater. 164 (2009) 1146-1151.

[43] H. Hasegawa, I.M.M. Rahman, M. Nakano, Z.A. Begum, Y. Egawa, T. Maki, Y. Furusho, S. Mizutani, Recovery of toxic metal ions from washing effluent containing excess aminopolycarboxylate chelant in solution, Water Res. 45 (2011) 4844-4854.

[44] L.F. Lindoy, The Chemistry of Macrocyclic Ligand Complexes, Cambridge University Press, New York, 1990.

[45] W. Walkowiak, C.A. Kozlowski, Macrocycle carriers for separation of metal ions in liquid membrane processes - A review, Desalination 240 (2009) 186-197.

[46] N. Nadaud, N. Lequeux, M. Nanot, J. Jové, T. Roisnel, Structural studies of tin-doped indium oxide (ITO) and $\mathrm{In}_{4} \mathrm{Sn}_{3} \mathrm{O}_{12}$, J. Solid State Chem. 135 (1998) 140-148.

[47] C.H. Yu, Q.T. Cai, Z.X. Guo, Z.G. Yang, S.B. Khoo, Inductively coupled plasma mass spectrometry study of the retention behavior of arsenic species on various solid phase extraction cartridges and its application in arsenic speciation, Spectrochim. Acta B 58 (2003) 1335-1349. 
(a) MRT-SPE types

TE 02: AnaLig TE 02; TE 03: AnaLig TE 03; TE 07: AnaLig TE 07 TE 13: AnaLig TE 13; PM 02: AnaLig PM 02

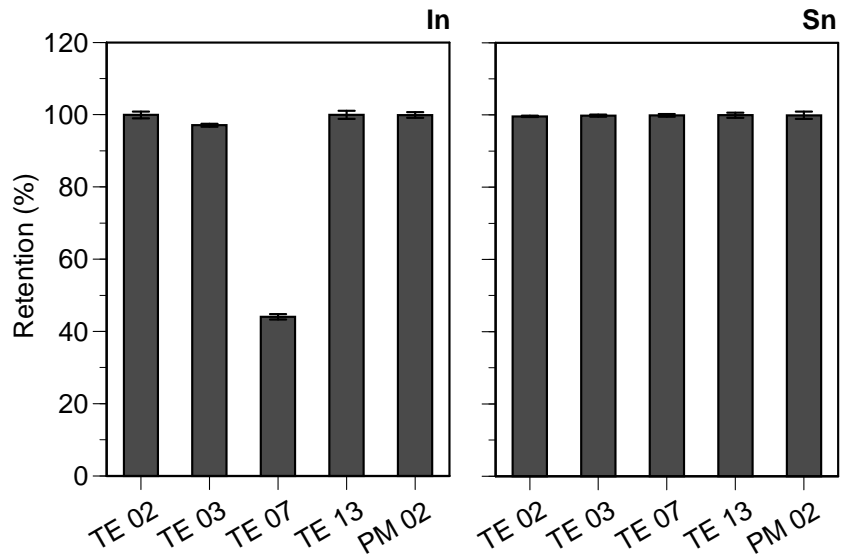

\section{(b) Other SPE-types}

C 100: Chelex-100, PA 1: NOBIAS Chelate PA-1, PB 1: NOBIAS Chelate PB-1, SC 1: NOBIAS Ion SC-1, SA 1: NOBIAS Ion SA-1

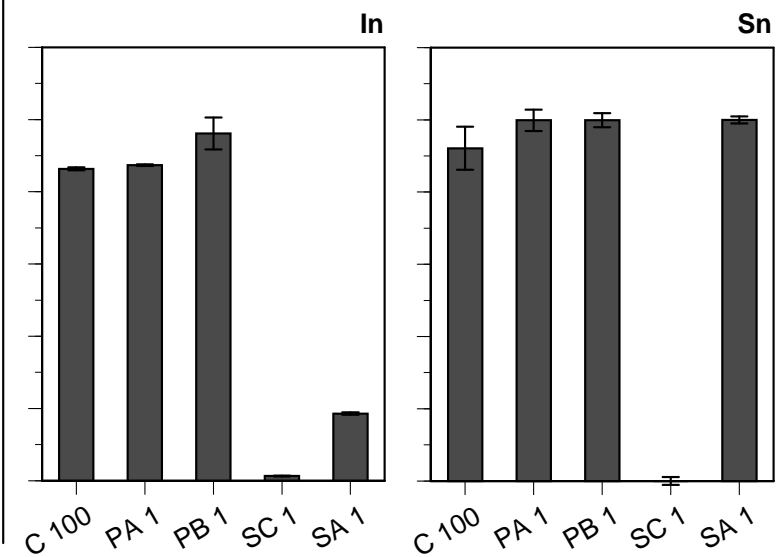

Figure 1: Comparative retention rate of indium and tin in (a) different MRT-SPE types, and (b) other SPE-types. Simulated solution of etching waste was the sample $(n=3)$ 


\section{(a) MRT-SPE types}

TE 02: AnaLig TE 02; TE 03: AnaLig TE 03; TE 07: AnaLig TE 07 TE 13: AnaLig TE 13; PM 02: AnaLig PM 02

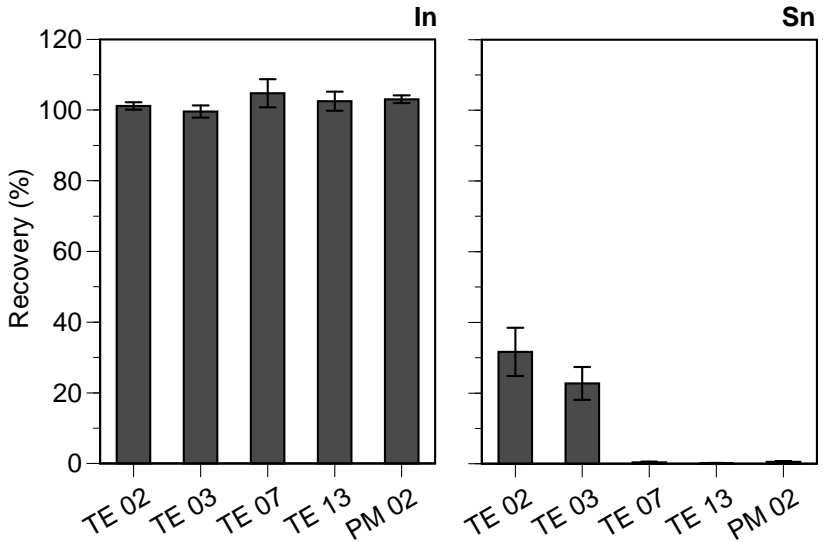

(b) Other SPE-types

C 100: Chelex-100, PA 1: NOBIAS Chelate PA-1, PB 1: NOBIAS Chelate PB-1, SC 1: NOBIAS Ion SC-1, SA 1: NOBIAS Ion SA-1

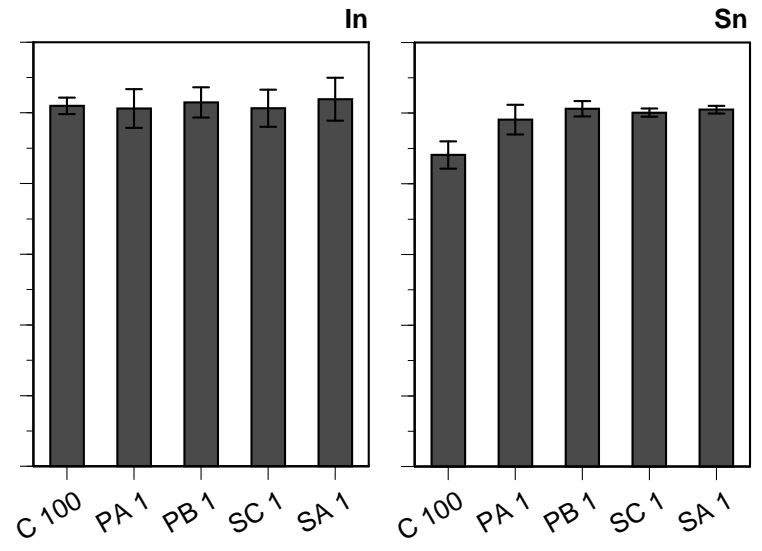

(c) Recovery of tin from the MRT-SPE types using different eluents

Elu 1: $1 \mathrm{~mol} \mathrm{~L}^{-1} \mathrm{HNO}_{3}(2 \mathrm{~mL})+6 \mathrm{~mol} \mathrm{~L}^{-1} \mathrm{HNO}_{3}(1 \mathrm{~mL})+$ Ultrapure water $(1 \mathrm{~mL})$

Elu 2: $6 \mathrm{~mol} \mathrm{~L}^{-1} \mathrm{HCl}(4 \mathrm{~mL})$, Elu 3: $1 \mathrm{~mol} \mathrm{~L}^{-1} \mathrm{HCl} / 10 \mathrm{mmol} \mathrm{L}^{-1}$ EDTA $(4 \mathrm{~mL})$
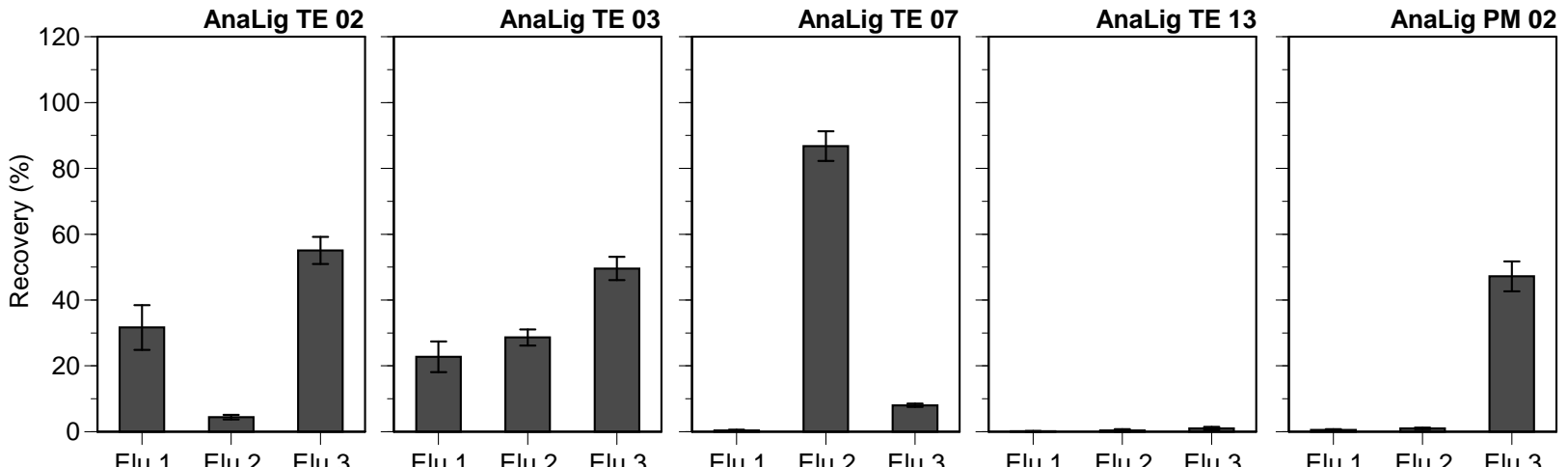

(d) Recovery of indium and tin with varying $\mathrm{HNO}_{3}$ concentration
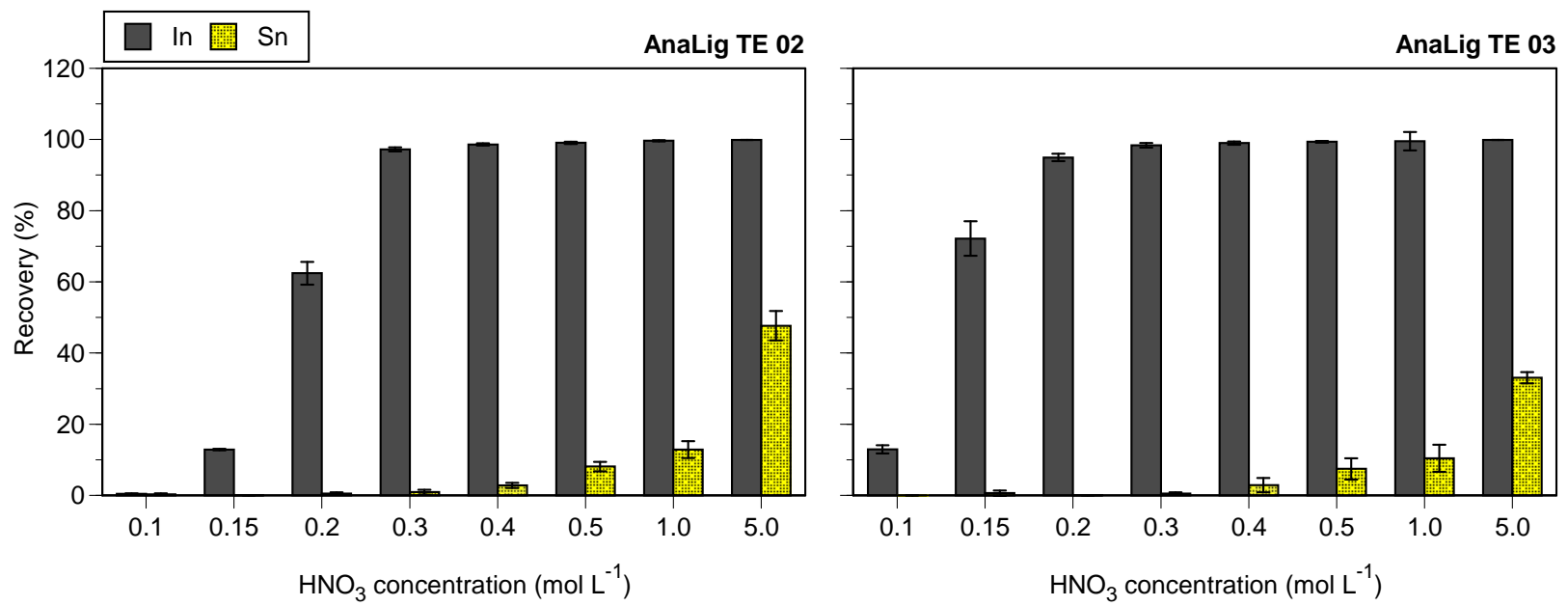

Figure 2: Comparative recovery rate (a) of indium and tin from different MRT-SPE types, (b) of indium and tin from the other SPE-types, (c) of tin from the MRT-SPE columns with different eluents, and (d) of indium and tin from the AnaLig TE 02 and TE 03 using 0.1 to $5 \mathrm{~mol} \mathrm{~L}^{-1} \mathrm{HNO}_{3}$. Simulated solution of etching waste was the sample $(n=3)$ 
(a) Matrix-component intensity

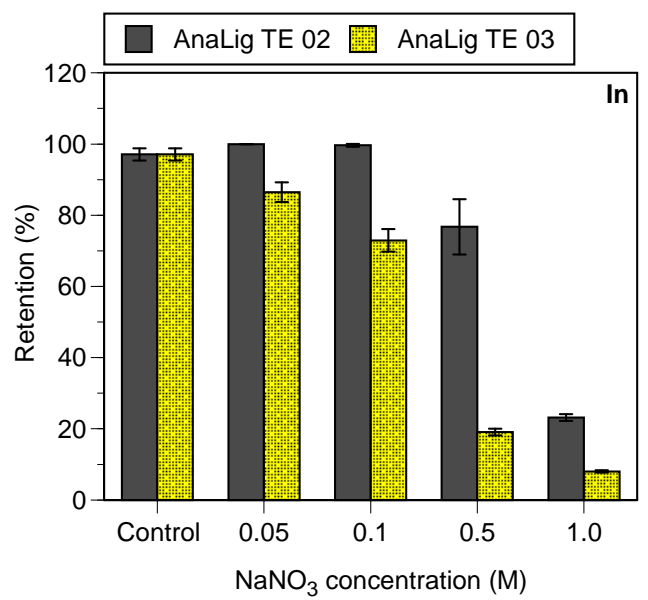

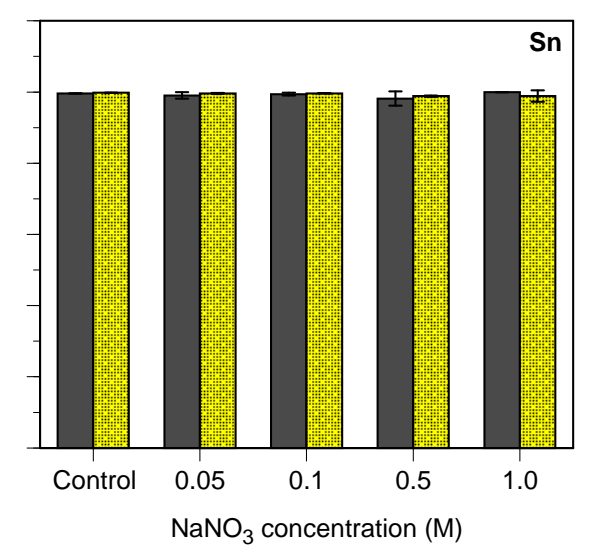

(b) Matrix-component diversity

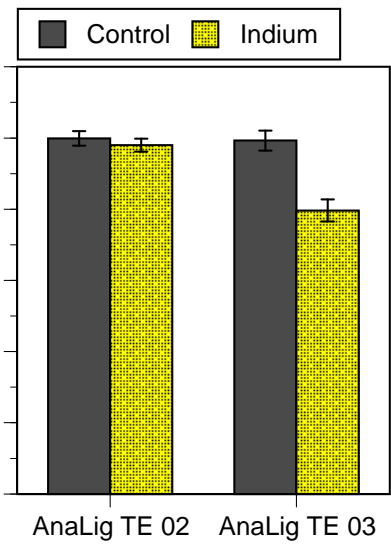

Figure 3: Comparative effect of matrix-component (a) intensity and (b) diversity on the retention rate of indium or tin in AnaLig TE 02 and AnaLig TE 03. The sample was the simulated solution of etching waste fortified with the $\mathrm{NaNO}_{3}$ or the PlasmaCAL multi-element solution $\left(20 \mathrm{mg} \mathrm{\textrm {L } ^ { - }}\right.$ ${ }^{1}$ element $\left.{ }^{-1}\right)$, while the same solution without the $\mathrm{NaNO}_{3}$ or any element was the control $(n=3)$ 


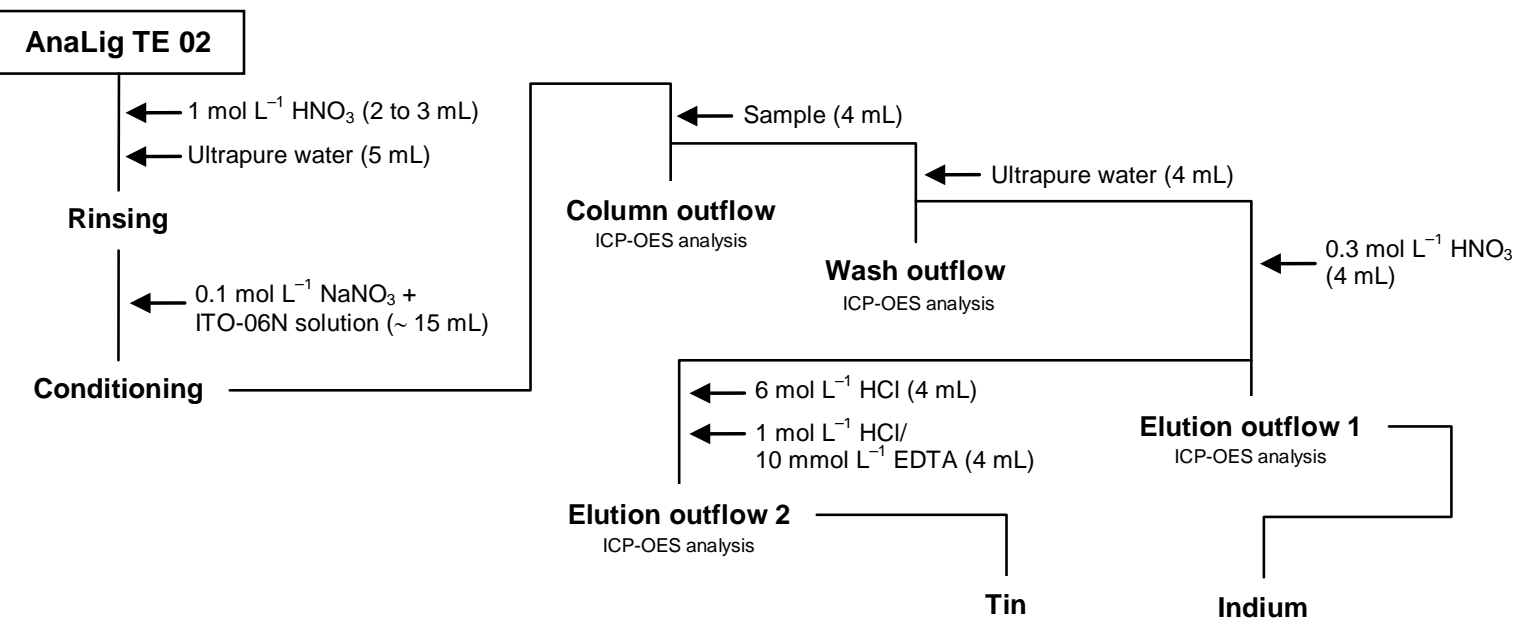

Figure 4: Schematic workflow diagram for the selective recovery of indium from the etching waste solution 
(a) Simulated etching waste solution

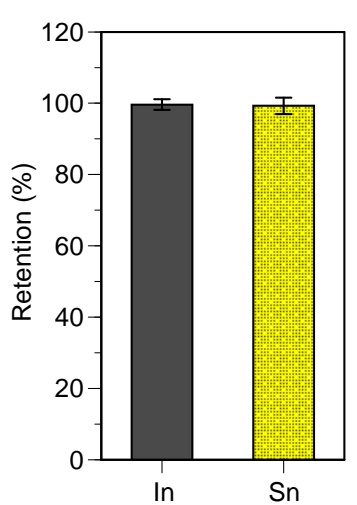

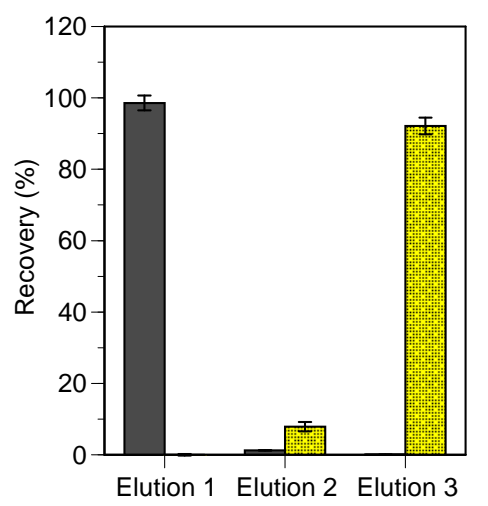

(b) Real etching waste solution

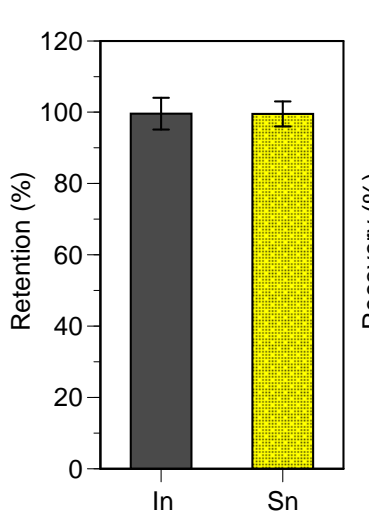

In $\mathrm{Sn}$

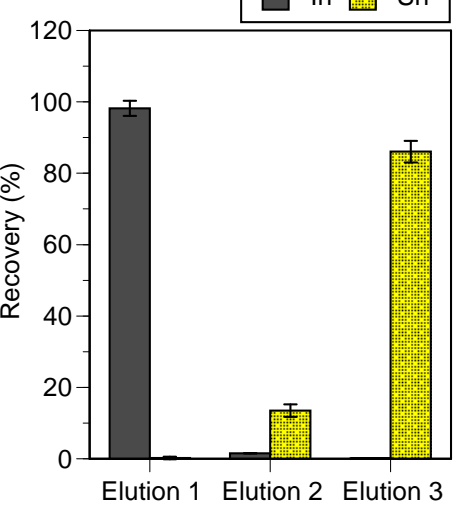

Figure 5: Selective recovery of indium using the AnaLig TE 02 MRT-SPE from the (a) simulated and (b) real etching waste solution $(n=3)$ 


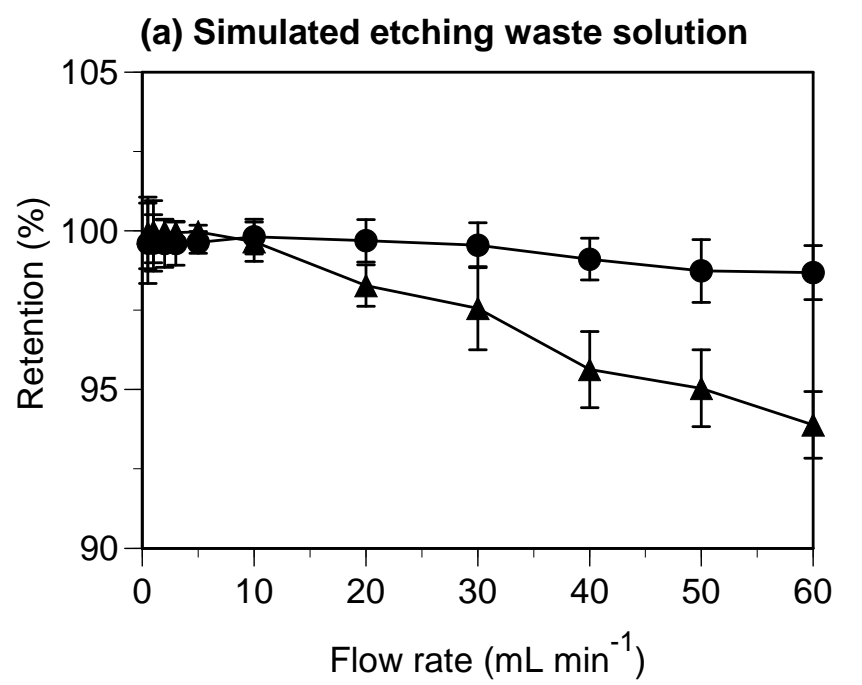

(b) Real etching waste solution

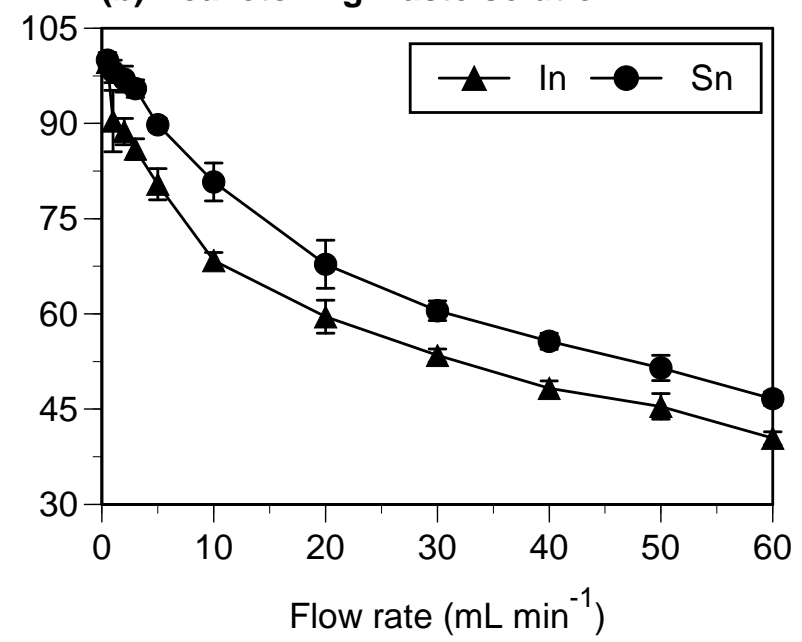

Figure 6: Effect of sample loading flow-rate on the comparative retention rate of indium and tin in the AnaLig TE 02 MRT-SPE from the (a) simulated and (b) real etching waste solution $(n=3)$ 


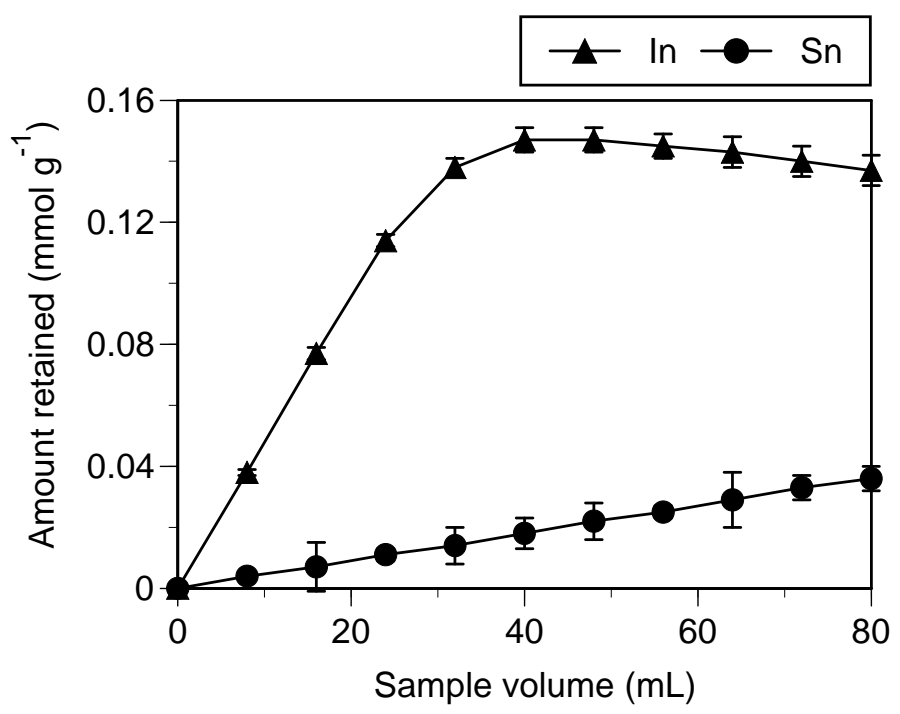

Figure 7: Comparative retention capacity of indium and tin in the AnaLig TE 02 MRT-SPE from the real etching waste solution $(n=3)$ 